\title{
CORRIGENDUM
}

\section{Variation in bacterial endosymbionts associated with the date palm hopper, Ommatissus lybicus populations - CORRIGENDUM}

\author{
S. Karimi, H. Izadi, M. Askari Seyahooei, A. Bagheri and \\ P. Khodaygan
}

doi:10.1017/S0007485317000633. Published by Cambridge University Press, 15 August 2017.

The authors apologise for an error in one of the published author names in the above publication. The author name A. N. Bagheri should have been written as A. Bagheri.

\section{Reference}

S. Karimi, H. Izadi, M. Askari Seyahooei, A. Bagheri and P. Khodaygan. Variation in bacterial endosymbionts associated with the date palm hopper, Ommatissus lybicus populations. Bulletin of Entomological Research. Published by Cambridge University Press, 15 August 2017. doi:10.1017/S0007485317000633. 